\title{
Digitech, Remix and Design Research for course /program-wide thinking and enhancement
}

\author{
Gail Casey and Annemieke Craig
}

Deakin University

\begin{abstract}
This paper describes the initial stage of an exploratory investigation in which the authors aim to build course/program-wide thinking into a process aimed at supporting, documenting and sharing technology-rich practices, innovative teaching and active student learning. The investigation uses a remix lens, in an attempt to creatively consider the manipulation of resources and approaches for reuse, while supporting consistency across subjects/units within a course. The authors are working within Deakin University's Course Enhancement Process, which is a major universitywide initiative that includes a framework of collaborative teams comprising academic and resourcing specialists working with faculty academic leaders. The Course Enhancement Process is flexible in its implementation and the authors aim to use the process to build a sustainable course-wide sharing and thinking approach within the Business and Law faculty at Deakin University, Australia.
\end{abstract}

Keywords: Course Thinking; Learning Design; Design Research, Remix, Active learning

\section{Introduction}

Universities face substantial change in a rapidly evolving global context. Boud and Associates (2009) argue that the challenges of meeting new expectations about academic standards, in the next decade and beyond, mean that assessment will need to be rethought and renewed. In considering many of these complexities, including quality standards and measures, Deakin University has implemented a process called 'Course Enhancement' (see, http://www.deakin.edu.au/learning/designing-assessing-andevaluating/enhancing-courses). This is a university-wide major initiative and one that also considers new age learning, diverse cohorts of students along with increasing multicultural needs for students.

Undergraduate courses, at Deakin, are usually of three years duration; some universities may call these 'programs'. Author 1 in her role as Course Enhancer, at Deakin, is involved in learning and assessment design while focusing on course-wide inputs and outputs of curriculum standards; she is supported by a resource team and works closely with course directors and subject/unit heads. Her role also aims to build teaching staff capacity and implement course enhancement processes and to provide tools that assist staff. Author 2 is the course director for Work Integrated Learning (WIL) in the faculty of Business and Law and has a focus on authentic and active learning with technology (Coldwell, Craig, \& Goold, 2011) and (Coldwell-Neilson, Beekhuyen, \& Craig, 2012).

In 2014, Author 1 was responsible for leading course enhancement with more than ten Business and Law courses and in 2015 this number has increased significantly. Author 1, as an experienced action researcher (Casey, 2013a, 2013b, 2013c; Casey \& Evans, 2011), considers, informally, that each of her courses is one action research cycle involving planning, acting, observing and reflecting. This cyclic approach is aimed at the continuous improvement of her own practice.

Designing a course at a university, as argued by Bahr and Lloyd (2011), is the easy part. They explain that this component can be exciting, creative and collegiate as well as providing opportunities for faculty members to work together in genuinely collaborative ways. However, they argue that after the first year or so of 
implementation, almost inevitably, the initial design starts to come unstuck, for many reasons including staffing changes, subtle and incremental migration of course resources, opportunistic inclusions of 'off the shelf' or subject/unit-based innovative teaching and learning approaches, and perhaps generally poor attention to detail with regard to the impact of new introductions and electives. They describe (p. 21) this effect as the 'parts' become more important than the 'whole' and faculty lose sight of course outcomes. The authors have seen this occur many times and, hence, aim to embed a course-wide thinking approach within their study.

This paper discusses the initial stages of the authors' exploratory study aimed at designing and testing of a course-wide thinking approach. It uses WIL, from within the course enhancement process, as an example of their approach.

\section{DigiTech and Remix}

The failure to embrace emerging technologies in higher education courses can lead to pedagogies that risk alienating a generation of learners (Herrington \& Parker, 2013). Coldwell et al. (2011) argue that the judicious use of appropriate technologies support the diverse needs of students. At Deakin University, it is expected that all subjects/units within a course (whether online, blended or face-to-face) develop their own online learning environment, as part of what is known as CloudDeakin (see, http://www.deakin.edu.au/students/clouddeakin). This aims to use located and cloud learning to provide accessible media-rich, interactive and active educational experiences (Deakin University, 2014b).

The authors use the word digitech to encapsulate the use of rich media and technologies. As part of Course Enhancement, course and subject/unit information is gathered and a document known as a 'Course Evidence Portfolio' (Deakin University, 2014a) is generated. This data is organised in a way that provides a starting point for course-wide thinking (see, http://www.deakin.edu.au/learning/designing-assessing-andevaluating/enhancing-courses). Author 1 then spends time with course directors and course teams to develop a clear and concise set of course priorities, learning outcomes and minimum standards. The faculty helps to ensure that these align with Deakin Graduate Learning Outcomes, accreditation requirements (where applicable) and the Australian Qualifications Framework (Deakin University, 2014c).

Author 1 finds the role of course enhancer a very challenging role, but one that continually offers snippets of excellent innovative teaching practice along with opportunities to gain insider knowledge from some of the most successful lecturers at the university. Being privileged to these resources comes with the responsibility to share insights to help build staff capacity. However, such resources rarely come packaged in a perfect bundle ready to embed in different subjects or courses; hence, this leads the authors to consider Markham's (2013) notion of remix. As a brief caveat, Markham (2013, p. 66) describes remix as a 'generative tool for thinking creatively'. The authors aim to use the concept of remix (generating, playing, borrowing, moving and interrogating) as a way of thinking about the reuse of resources; in particular, digital resources. 


\section{The Study: Course thinking using Educational Design Research}

In considering the complex demands surrounding higher education, the authors have aligned their study with Deakin's 'LIVE the future agenda 2020' (Deakin University, 2014b) and searched for a research methodology that includes improvement cycles of planning, acting and reflection in order to cater for the changing nature of higher education.

Herrington, Reeves, and Oliver (2010) argue that it is almost impossible to conceive of any authentic learning endeavour, in higher education today, that does not take advantages of the affordances of computers and the Internet. They promote an educational design research (also known as design-based or design research) method when integrating an authentic e-learning approach and this uses iterative cycles; although this requires teachers to take risks and authentic tasks must be well supported with guidance and resources.

Design-based research evolved near the beginning of the $21^{\text {st }}$ century and was heralded as a practical research methodology that could effectively bridge the chasm between research and practice in formal education (Anderson \& Shattuck, 2012). In educational design research it is common practice to develop and implement curriculum materials in order to address a particular educational problem (Tolboom \& Kuiper, 2014). One of the main criticisms of educational design research is that the report of the evaluation is qualitative and, as Tolboom and Kuiper (2014) point out, this could lead to conclusions which are very dependent on the conditions in a specific part of the sample. Educational design research was chosen for this study because it is a methodology designed by and for educators that seeks to increase the impact, transfer and translation of education research into improved practice (Anderson \& Shattuck, 2012). It also, as explained by Anderson and Shattuck (2012), stresses the need for theory building and the development of design principles that guide, inform and improve both practice and research in educational contexts.

In considering the suitability of design research within the Course Enhancement Process, it is useful to understand the four stages of Course Enhancement at Deakin (see, $\quad$ http://www.deakin.edu.au/learning/designing-assessing-andevaluating/enhancing-courses). These stages are also outlined in the Course Evidence Portfolio, mentioned earlier. Such a document highlights how curriculum standards are designed to guide course development and enhancement. It also provides a document that helps to understand the importance of course-wide thinking and why the authors aim to investigate ways to integrate a course-wide thinking approach within their WIL study.

The authors are guided by Herrington et al. (2010) and Reeves (2006, p. 59) 'design research approaches in educational technology' combined with approaches from Anderson and Shattuck (2012). The following four elements describe the initial thoughts and research planning by the Authors for Work Integrated Learning research using a design research approach.

\section{Analysis of practical problems by researchers and practitioners in collaboration}

Work Integrated Learning (see, http://www.deakin.edu.au/buslaw/enhancestudy/work-integrated-learning), is a series of ten subjects/units that are integrated into a range of Business and Law core, co-core and elective courses. Some can also be 
incorporated as electives in undergraduate courses across Deakin. More information on these subjects/units can be found on the Work Integrated information flyer at http://www.deakin.edu.au/_data/assets/pdf_file/0009/236079/WIL-web.pdf.

All ten subjects/units are fully online and available during any study period (Deakin courses run over three trimesters in a twelve month period-rather than the usual semester approach at most universities). All ten WIL subjects/units are aimed at maximising the employability of students within Business and Law.

As part of an increased emphasis on employability of graduates, at Deakin, Author 2, as course director of WIL, needs to ensure that Work Integrated learning can be scaled up as more courses seek to integrate opportunities for student employability. Work Integrated learning must now be scalable to cater for an increasing demand. This includes upgrading the WIL online learning environment to support increased dissemination of information as well as building shared student knowledge banks to support peer-to-peer learning and revisiting assessment tasks to ensure consistency and clarity as the number of required assessors increases. A collaborative team of staff is being constructed including experts in digital literacies and language skills to support issues surrounding the large international student cohort. For strength and consistency, it is important that the thinking and approaches taken by this team are course-wide.

\section{Development of solutions - authentic eLearning design and effective assessment}

All ten subjects/units within Work Integrated Learning are fully online and, therefore, the authors aim to take advantage of the characteristics of the Internet and its capacity to allow for a worldwide community to exchange ideas and to learn from each other (Davidson \& Goldberg, 2009).

In developing a solution for the Work Integrated Learning problems discussed, Deakin's Graduate learning Outcomes (see, http://www.deakin.edu.au/learning/designing-assessing-and-evaluating/graduatelearning-outcomes) provide the theoretical underpinning for the capabilities that graduates acquire and demonstrate at the completion of any course. Also, the following nine points, in italic, outline Herrington et al. (2010) characteristics of authentic learning. Each of these are followed by the Authors' attempt to align these with the planning for Work Integrated Learning.

\section{Elements of Authentic Learning:}

1. Provide authentic contexts that reflect the way the knowledge will be used in real life - structure lectures, tutorials and online examples around real people involved in real-life business problems as well as solutions.

2. Provide authentic tasks - use Work Integrated learning and simulations wherever possible. When designing assessment, carefully consider what the graduate, in the specific area, will be doing and how they will be evaluated in the work-place setting.

3. Provide access to expert performances and the modelling of processes - where possible, provide students with annotated samples of students' past assessment of a pass and credit standard.

4. Provide multiple roles and perspectives - use peer-to-peer online discussion and sharing to generate a knowledge bank of experiences and perspectives.

5. Support collaborative construction of knowledge - as in point 4. 
6. Promote reflection to enable abstractions to be formed - provide opportunities for students to give serious thought and consideration to the way they are thinking, acting and/or reacting.

7. Promote articulation to enable tacit knowledge to be made explicit - as in point 4.

8. Provide coaching and scaffolding by the teacher at critical times - use the library staff and language and literacy staff as collaborators for scaffolding assessment design.

9. Provide for authentic assessment of learning within the tasks - as in point 2.

In adding further context for effective learning, the authors see the need to identify how effective learning takes place and, therefore, there is a need to carefully consider aspects of assessment. In considering the demands and changes within higher education, Boud and Associates (2009) provide seven propositions for assessment reform in higher education developed. These were developed by a team of experienced assessment researchers, academic development practitioners and senior academic managers aimed at identifying current best thinking about the ways assessment will need to address immediate and future demands. These propositions are:

1. Assessment is used to engage students in learning that is productive.

2. Feedback is used to actively improve student learning.

3. Students and teachers become responsible partners in learning and assessment.

4. Students are inducted into the assessment practices and cultures of higher education.

5. Assessment for learning is placed at the centre of subject and program design.

6. Assessment for learning is a focus for staff and institutional development.

7. Assessment provides inclusive and trustworthy representation of student achievement.

“Assessment is the making of judgements about how students' work meets appropriate standards" (Boud \& Associates, 2009, p. 1). As discussed by Boud and Associates (2009), students themselves need to develop the capacity to make judgements about both their own work and that of others in order to become effective continuing learners and practitioners. These seven points, combined with Herrington et al. (2010) nine characteristics of authentic learning make sixteen elements that the authors aim to use as the foundations of theory for this design research study.

\section{Iterative Cycles}

The iterative cycles, when implementing design research, need to involve testing and refinement, but underlying each cycle, for the authors, is a drive for sustainable improvement involving course-wide thinking. Lecturers and academics are, in many cases, time poor. With this in mind, Herrington et al. (2010, p. 22) propose the following questions to ask when 'developing guidelines for developing authentic tasks'. These are very helpful to revisit after during each cycle. Their foci help to drive the development of the solution.

1. What kinds of activities are conducted, in the real world, that use the knowledge, skills and attitudes that are the focus of the course?

2. How is this knowledge applied to answer real-world questions and solve realworld problems? 
In returning to our study involving Work Integrated Learning, an iterative cycle would occur in a trimester. The aim is, initially, to trial and test ideas, collaboratively devised, within one subject/unit. After reflection and further planning, a broader course-wide approach would occur after each cycle.

\section{Reflection to produce 'Design Principles'}

With the approach discussed, reflection, including further planning is paramount for the successful integration of other WIL units into the design research study. Design principles are needed in order to effectively build course-wide thinking.

\section{Discussion and conclusion}

In this early stage of the study, this paper describes the need for course wide thinking in higher education. The approach taken and the reasons behind this has been discussed. A number of further documents and resources can also be made available. In the authors' search for a methodology that has the potential to deal with complex learning environments and best practice, Design Research is showing excellent potential through its ability to integrate the development of solutions to practical problems in learning environments, while identifying reusable design principles (Reeves, 2006).

The concept of reuse is ideal for Author 1's role as course enhancer. It also aligns well with the notion of remix while helping to think more creatively in the way the different elements are reused, manipulated and redesigned.

In meeting Reeves' (2006) call for the educational technology research community to adopt design research methods more widely, the authors aim to use the iterative cycles within the process to develop 'rapid prototyping with on-going improvement and redesign’ (Herrington \& Teras, 2014, p. 232) for Work Integrated Learning.

This initial stage of this exploratory study has moved past what could be called a 'good idea' and into systematic and pedagogically sound research. It is an approach that has the potential to offer a 'best practice' approach (Anderson \& Shattuck, 2012, p. 24) while taking into account complex learning environments. This paper has used Work Integrated Learning as the focus of this study. The Authors' longer-term goal is to expand this research into further courses and use the Work Integrated learning study to inform the development of other courses. The ultimate goal is to work towards a sustainable approach to course enhancement that involves self-generating iterative cycles of reflection, analysis and redevelopment of solutions: an approach that we hope will lead to engaging, effective and efficient courses with a shared understanding of graduate learning outcomes.

\section{References}

Anderson, T., \& Shattuck, J. (2012). Design-based research: A decade of progress in education research. Educational Researcher, 41(1), 16-25.

Bahr, N., \& Lloyd, M. (2011). Course Cohesion: An elusive goal for tertiary education. Journal of Learning Design, 4(4), 21-30. 
Boud, D., \& Associates. (2009). Assessment 2020: Seven propositions for assessment reform in higher education. http://www.uts.edu.au/sites/default/files/Assessment2020_propositions_final.pdf

Casey, G. (2013a). Building a student-centred Learning framework using social software in the middle years classroom: An action research study. Journal of Information Technology Education: Research, 12, 159-189. http://www.jite.org/documents/Vol12/JITEv12ResearchP159-189Casey1186.pdf

Casey, G. (2013b). Interdisciplinary Literacy through Social Media in the Mathematics Classroom: an Action Research Study. Journal of Adolescent and Adult Literacy, 57(1), 58-69. doi: 10,1002

Casey, G. (2013c). Social media in the classroom: a simple yet complex hybrid environment for students. Journal of Educational Multimedia and Hypermedia, 22(1), 5-24.

Casey, G., \& Evans, T. (2011). Designing for learning: Online social networks as a classroom environment. The International Review of Research in Open and Distance Learning, 12(7), 1-26. http://www.irrodl.org/index.php/irrodl/article/view/1011 and ( published in Spanish) http://bdistancia.ecoesad.org.mx/contenido/numeros/numero7/presencia_01.html.

Coldwell, J., Craig, A., \& Goold, A. (2011). Using e Technogies for active learning. Interdisciplinary Journal of Information, Knowledge, and Management, 6, 1-12.

Coldwell-Neilson, J., Beekhuyen, J., \& Craig, A. (2012). Which e-learning technolgy is right for me? International journal of emerging technogies in learning, 7(2), 1321.

Davidson, C., \& Goldberg, D. (2009). The Future of Learning Institutions in a Digital Age: Massachusetts Institute of Technology.

Deakin University. (2014a). Course evidence portfolio. http://www.deakin.edu.au/_data/assets/pdf_file/0018/229140/Course-evidenceportfolio-2014.pdf

Deakin University. (2014b). LIVE the future agenda 2020. http://www.deakin.edu.au/_data/assets/pdf_file/0004/6961/strategic-planbooklet-print.pdf

Deakin University. (2014c). Stage 2: Assessment and learning design. from http://www.deakin.edu.au/learning/designing-assessing-andevaluating/enhancing-courses/stage-2

Herrington, J., \& Parker, J. (2013). Emerging technologies as cognitive tools for authentic learning. British Journal of Educational Technology, 44(4), 607-615. doi: 10.1111/bjet.12048

Herrington, J., Reeves, T., \& Oliver, R. (2010). A guide to authentic e-learning. New York and London: Routledge.

Herrington, J., \& Teras, H. (2014). Neither the frying pan nor the fire: In search of a balanced authentic e-Learning design through an educationla design research process. International Review of Research in Open \& Distance Learning, 15(2), 232-253.

Markham, A. (2013). Remix culture, remix methods: Reframing qualitative inquiry for social media contexts. In M. Giardiana \& N. Denzin (Eds.), Global Dimensions of Qualitative Inquiry (pp. 63-81). Walnut Creek, CA: Left Coast Press. 
Reeves, T. (2006). Design research from a technolgy perspective. In J. Van Den Akker, K. Gravemeijer, S. McKenney, \& N. Nieveen (Eds.), Educational Design Research (pp. 52-66). London: Routledge.

Tolboom, J., \& Kuiper, W. (2014). Quantifying correspondence between the intended and the implemented intervention in educational design research. Studies in Educational Evaluation, 43(0), 160-168. doi: http://dx.doi.org/10.1016/j.stueduc.2014.09.001 